\title{
Rapid Distribution of Tryptophol (3-Indole Ethanol) to the Brain and Other Tissues
}

\author{
Eain M. Cornford, William D. Bocash, Leon D. Braun, Paul D. Crane, \\ and William H. OldENDORF, Research Service, Veterans Administration Medical \\ Center, Brentwood, Los Angeles, California 90073; and Departments of Neurology \\ and Psychiatry, University of California at Los Angeles School of Medicine, \\ Los Angeles, California 90024. \\ Austin J. MACINNis, Department of Biology, University of California at Los Angeles, \\ Los Angeles, California 90024
}

\begin{abstract}
A B S T R A C T Tryptophol (3-indole ethanol) is a compound which induces sleep, and is formed: $(a)$ in the liver after disulfiram treatment, and $(b)$ by the parasite in trypanosomal sleeping sickness. We prepared, purified, and characterized radiolabeled tryptophol for the purpose of defining its tissue distribution in animals. Tryptophol was found to be highly lipophilic, with an octanol:water partition coefficient of 29.8. Brain extraction, determined after intracarotid injection, was high (brain uptake index $=117 \pm 3.5 \%$ ), and nonsaturable, suggesting the absence of a carrier system. After intravenous administration, tryptophol distribution to tissues correlated with relative blood flow. More than $85 \%$ of the radioactivity remaining in brain $2-5 \mathrm{~min}$ after intravenous injection co-migrated with tryptophol standards when analyzed by thin-layer chromatography. Other evidence suggested that tryptophol binds to serum and in vivo may be stripped from serum albumin and taken up by brain in a single capillary transit. Our study suggests that in states such as trypanosomal sleeping sickness or disulfiram treatment, remotely formed tryptophol gains ready access to brain (it is $100 \%$ cleared in a single capillary passage), and could thus cause somnolence.
\end{abstract}

\section{INTRODUCTION}

The reduction of indole acetaldehydes to their respective alcohols was postulated in 1916 by Guggenheim and Loffler (1). Tryptophol was isolated as a tryptophan metabolite of yeast by Ehrlich in 1912 (2) and first identified from mammals as a tryptamine metabolite in rabbit liver (1). Subsequently, 5-hydroxytryptophol was identified as a serotonin (5-hydroxytryptamine)

Received for publication 3 November 1978 and in revised form 5 February 1979. metabolite in rats $(3,4)$, bovine pineals $(5)$, and humans, both in vivo (6) and in brain tissue in vitro (7). Ethanolinduced modification of the metabolism of biogenic indole amines results in the increased production of tryptophol compounds, specifically 5-hydroxytryptophol (4, 8-13). Disulfiram (Antabuse, Ayerst Laboratories, New York) treatment in rats induces the formation of tryptophol (14) and increased quantities of 5-hydroxytryptophol (10).

Tryptophol compounds are known to induce sleep in laboratory mammals $(15,16)$ and chicks (17). In the latter study, Taborsky (17) selected young chickens believing that because the adult blood brain barrier $(\mathrm{BBB})^{1}$ specifically excluded central nervous system(CNS) active substances such as tryptophol, it would be appropriate to use 1-14-d-old chicks. These young animals were believed to have an incomplete BBB (on the basis of electroencephalographic studies), and it was postulated that under these conditions penetration of tryptophols would be observed.

Stibbs and Seed $(18,19)$ demonstrated that Trypanosoma brucei gambiense, a blood parasite that causes trypanosomal sleeping sickness, converts tryptophan into two metabolites, indole lactic acid and indole ethanol (tryptophol). In addition to having immunosuppressive qualities (20), current evidence suggests tryptophol is responsible for the sleep syndrome characteristic of the disease $(18,19)$. Vogel $(21)$ reported that 5 -methoxytryptamine did not readily cross the BBB, and this precipitated the suggestion (22) that tryptophol compounds such as 5-methoxytryptophol may not cross

\footnotetext{
${ }^{1}$ Abbreviations used in this paper: BBB, blood brain barrier; BSA, bovine serum albumin; BUI, brain uptake index; CNS, central nervous system; $K_{d}$, dissociation constant; MBD, mean body distribution; $R_{f}$, retention ratio (relative to the solvent front); TLC, thin-layer chromatography.
} 
the BBB. Stibbs and Seed (18) consequently suggested that tryptophol formed by trypanosomes which had invaded the cerebrospinal fluid was responsible for the sleep syndrome associated with the disease.

In this study we have prepared radiolabeled tryptophol for the purpose of defining brain uptake in vivo after intracarotid injection, and for determining the distribution of this compound to various body tissues after intravenous administration in the rat.

\section{METHODS}

Tryptophol was purchased from Sigma Chemical Co. (St. Louis, Mo.). A 300-mg sample was commercially tritiated (Biochemical Nuclear Corporation, Burbank, Calif.) by the Wilzbach method. The tritiated compound was repeatedly washed to remove labile tritium, charcoal filtered, and purified by chromatographic separation on preparative silica gel plates in a benzene:acetic acid:water (172:25:3) solvent system (18).

The purified tryptophol was dissolved in methanol or in pure (200-proof) ethanol and an equal volume of twice-distilled water was added. Radiochemical purity of the isotope was rechecked by thin-layer chromatography (TLC) on Quantagram plates (Pierce Chemical Co., Rockford, Il.) and isotopic scanning with a Berthold Varian radioscanner (Varian Associates, Instrument Div., Palo Alto, Calif.) after each laboratory procedure. For intracarotid injections, a quantity of ethanolic tryptophol was subjected to evaporation under nitrogen and diluted so that the working $\left[{ }^{3} \mathrm{H}\right]$ tryptophol solution contained $<0.5 \%$ ethanol. Other isotopes $(113 \mathrm{~m}$ Indium and $\left[{ }^{14} \mathrm{C}\right]$ butanol) were obtained commercially (New England Nuclear, North Billerica, and Boston, Mass., respectively). Methods of isotope preparation and determination of brain uptake are detailed elsewhere (23). Briefly, the $113 \mathrm{~m}$-Indium was bound to EDTA and employed as an internal reference isotope defining the vascular space of brain and other tissues; it does not readily diffuse from the circulatory system in the short time periods employed in this study. Butanol is a second internal reference isotope, but a highly diffusible molecule which readily moves from capillaries into the extravascular fluids. Wistar rats $(250-350 \mathrm{~g})$ used in this study were purchased from Hilltop Lab Animals, Inc. (Chatsworth, Calif.), fed lab chow and water ad libitum, and maintained with the light photoperiod beginning at 7 a.m. and ending at 7 p.m.

Partition coefficients. The partition coefficient of radiolabeled $\left[{ }^{3} \mathrm{H}\right]$ tryptophol was determined in an octanol:buffered Ringer's saline system as described previously (24).

Tissue distributions. Weighed aliquots of $\left[{ }^{3} \mathrm{H}\right]$ tryptophol and $113 \mathrm{~m}$-Indium were injected into the saphenous vein of male rats under light ether anesthesia. Aliquots of the injectate were sampled to define the ratio of isotopes administered, disintegrations per minute/gram in the injectate and the total disintegrations per minute of each isotope administered to the rat. Animals were weighed and were decapitated $120 \mathrm{~s}$ after injection. Weighed samples of blood plasma, skin, nervous system, thyroid, thymus, lung, digestive system tissues, muscles, kidneys, adrenals, lymph nodes, gonads, spleen, and urine were routinely prepared for liquid scintillation counting.

Aliquots of the forebrain were analyzed to determine what fraction of the ${ }^{3} \mathrm{H}$ isotope remained as tryptophol $2 \mathrm{~min}$ after intravenous injection. In separate studies, aliquots of brain, liver, lung, pancreas, and plasma were taken from similarly sized male rats that had been killed 2 and $5 \mathrm{~min}$ after intravenous injection of $\left[{ }^{3} \mathrm{H}\right]$ tryptophol (about $100 \mu \mathrm{Ci}$ ). Weighed tissue samples of about $0.2 \mathrm{~g}$ wet weight were homogenized in $10 \mathrm{ml}$ of $10 \mathrm{mM}$ Tris-HCl; Trizma, Sigma Chemical Co., containing $0.02 \%$ sodium-azide, and centrifuged at $1,500 \mathrm{~g}$ for $10 \mathrm{~min}$. Supernatant solutions and pellets were separated, the pellets washed with $5 \mathrm{ml}$ of Tris-azide buffer, and each pellet digested for routine liquid scintillation counting. The supernates from each pellet were combined and washed twice with an equal volume of ether. Aliquots of both the ether and Tris-azide solutions were counted for ${ }^{3} \mathrm{H}$ disintegrations per minute. The (tryptophol-containing) ether layers were then dried down to a small volume and subjected to TLC analysis (with comparison to known standards) in ether:hexane (1:1) and benzene:acetic acid:water (172:25:3) solvent systems. Plasma samples $(1-2 \mathrm{ml})$ were directly diluted with Tris-azide to a total vol of $15 \mathrm{ml}$, the tryptophol extracted with ether washes and these samples were then handled identically to the tissue supernates. (Previous trials using tissues obtained from normal rats mixed with a known quantity of $\left[{ }^{3} \mathrm{H}\right]$ tryptophol at the time of homogenization, indicated that $87-92 \%$ of the tryptophol could be recovered intact by this procedure.)

Liquid scintillation counting. As soon as the tissue had been digested with an organic base (Soluene-100, Packard Instrument Co., Inc., Downers Grove, Il.) $10 \mathrm{ml}$ of scintillation fluid, Instagel, (Packard Instrument Co., Inc.) was added to each vial and the $\mathrm{pH}$ of the solution brought to near neutrality by the addition of $\cong 75 \mu \mathrm{l}$ of acetic acid. The samples were counted for Indium content (1-min counts) in a Packard Tricarb 3390 scintillation counter with the windows set as described by Oldendorf and Szabo (25). Days later, after all the $113 \mathrm{~m}$-Indium $\left(t_{1 / 2}=100 \mathrm{~min}\right)$ had decayed, the vials were recounted for tritium and ${ }^{14} \mathrm{C}$ content. The net Indium counts are obtained by subtraction and appropriate decay correction. (When vials are sequentially counted for Indium disintegrations in $1 \mathrm{~min}$, each successive vial must be decay-corrected for the elapsed time, i.e., $1.0 \mathrm{~min}$ plus the time required by the machine to change samples, i.e., $0.3 \mathrm{~min}$ ).

The brain uptake index (BUI) of tritiated tryptophol was determined from the ratio:

$\mathrm{BUI}=100 \% \times\left(\frac{{ }^{3} \mathrm{H} /{ }^{14} \mathrm{C} \text { in brain }}{{ }^{3} \mathrm{H} /{ }^{14} \mathrm{C} \text { in mix }}\right)-\left(\frac{113 \mathrm{~m} \mathrm{In} /{ }^{14} \mathrm{C} \text { in brain }}{113 \mathrm{~m} \mathrm{In} /{ }^{14} \mathrm{C} \text { in mix }}\right)$.

The dissociation constant $\left(K_{\mathrm{d}}\right)$ of $\left[{ }^{3} \mathrm{H}\right]$ tryptophol was determined in vitro after dialysis of 1 vol of $3 \%$ bovine serum albumin (BSA) against $10 \mathrm{vol}$ of Ringer's saline (with $10 \mathrm{mM}$ Hepes buffer, $\mathrm{pH} 7.5$, and $0.05 \%$ sodium azide) and (calculated from the ratio:

$K_{\mathrm{d}}=\left(\frac{\% \text { free (in saline) tryptophol }}{\% \text { bound (in BSA) tryptophol }}\right)$

$\times$ (BSA concn in micromoles).

The percent mean body distribution (\% MBD) (26) is defined as:

Tissue \% MBD $=\left(\frac{\text { net tritium dpm/g (tissue) }}{\text { total tritium dpm injected } / \text { total rat wt g }}\right) \times 100 \%$.

Similarly, in this study, tissue:plasma $(\mathrm{T} / \mathrm{P})$ ratios were determined as previously described (26) from the ratio:

$$
\mathrm{T} / \mathrm{P}=\left(\frac{\text { Net }{ }^{3} \mathrm{H} \text { dpm/g (tissue) }}{\text { Net }{ }^{3} \mathrm{H} \text { dpm/g (plasma) }}\right) .
$$

Analysis of data. Unless otherwise indicated all values are presented in the form of a mean, standard deviation (SD), and number $(n)$ of observations. Counts per minute (cpm) recorded on the liquid scintillation counter are converted to 
true disintegrations per minute by cubic regression analysis on a Hewlett-Packard 9820 programmable calculator (Hewlett-Packard Co., Palo Alto, Calif.).

\section{RESULTS}

The tritiated tryptophol was characterized as a radiochemically pure isotope in TLC by the appearance of a single peak containing $>97 \%$ of the radioactivity. On Quantagram plates, TLC analyses of: ( $a$ ) tryptophol obtained from Sigma Chemical Co., $(b)$ the tritiated tryptophol, and $(c)$ a mixture of our tritiated tryptophol plus the unlabeled tryptophol from Sigma Chemical Co. all co-migrated (in the solvent systems employed by Stibbs and Seed [18]), and were recognized as single discrete spots upon staining with Van Urk's Reagent. In both $n$-butanol:acetic acid:water $(4: 1: 1)$ and benzene:acetic acid:water (125:72:3) we observed a retention ratio $\left(R_{\mathrm{f}}\right)$ of 0.91 . Values in the range of $0.52-$ 0.55 were observed in benzene:methanol $(3: 1)$. Because Raj and Hutzinger (27) reported an $R_{f}$ of 0.84 for the 2,4-dinitrophenylsulfenyl chloride derivitive of tryptophol in the latter solvent system, further characterization and purity confirmation (of our tritiated tryptophol) was performed in other solvent systems. Smith and Wortis (14) indicate in isopropanol-7N ammonia (4:1) tryptophol has an $R_{\mathrm{f}}$ of 0.9 . In separate trials we observed a single peak containing $>97 \%$ of radioactivity and confirmed their $R_{\mathrm{f}}$ values $(0.897,0.897,0.917,0.907$, and 0.896). Additionally, in hexane:acetone (50:50) we observed a single radioactive spot and $R_{f}$ values of 0.856 and 0.847 .

Partition coefficient. The partition coefficient of tryptophol was determined (after triplicate rinses of each phase) to be 29.8 (in Octanol:Ringer's saline) indicating the lipophilic properties of this compound.

Sleep induction in rats. A dose of $160 \mathrm{mg} / \mathrm{kg}$ of tryptophol, dissolved in $30 \%$ ethanol at a concentration of $100 \mathrm{mg} / \mathrm{ml}$, induced sleep in rats 5-6 min after intraperitoneal injection (confirming previous studies [15] performed on mice). The same dose of tryptophol, administered in an octanol (200 $\mathrm{mg}$ tryptophol $/ \mathrm{ml})$ solution, induced a relatively lighter state of sleep within 7-10 min which lasted $0.5-1.0 \mathrm{~h}$. A tryptophol-induced drop in rectal temperature (from $39^{\circ} \mathrm{C}$ preinjection to $35.5^{\circ} \mathrm{C}$ at $30 \mathrm{~min}$ postinjection) appears to be a similar phenomenon to that seen in barbiturate-anesthetized rats (28). Seed et al. (16) also observed in mice that tryptophol produced a reduction in body temperature which was not significant at the 5\% confidence level. When tryptophol was administered in a propylene glycol solution we observed a significant reduction in body temperature $\left(1.61 \pm 0.5^{\circ} \mathrm{C}\right) 10 \mathrm{~min}$ after injection and also at $30 \mathrm{~min}$ after injection $\left(2.22 \pm 0.94^{\circ} \mathrm{C}\right)$. In both instances, these changes were statistically significant $(P<0.01)$ as measured by Dunnett's $(29)$ modified $t$ test.
Brain uptake indices. The brain uptake index of a trace concentration of tryptophol (relative to butanol) was determined to be $117 \pm 3.5 \%$. The addition of 1 or $10 \mathrm{mM}$ unlabeled tryptophol to the injectate resulted in no consistent reduction in brain uptake (Table I), suggesting that tryptophol uptake is not accomplished by a saturable, carrier-mediated process.

The observation that the apparent BUI increases with time of decapitation $(5 \mathrm{~s}<15 \mathrm{~s}<30 \mathrm{~s})$ might be attributed to a relatively faster initial washout rate of butanol than tryptophol (Table I). By 2-4 min, the relative concentrations of tryptophol and butanol approximate those seen $5 \mathrm{~s}$ after intracarotid injection, suggesting similar relative washout rates over this time period.

The apparent reduction in brain uptake of tryptophol when $50 \%$ normal rat serum is included in the injectate (Table I) suggested that tryptophol may bind to elements in serum. Confirmation of this possibility was sought by determining the dissociation constant $\left(K_{\mathrm{d}}\right)$ in vitro. After dialysis for $2 \mathrm{~h}$ at $37^{\circ} \mathrm{C}, 93.8 \%$ of the tryptophol remained bound to the BSA and $6.22 \%$ was free $\left(K_{\mathrm{d}}=2.9 \mu \mathrm{M}\right)$. Overnight dialysis $(17 \mathrm{~h})$ at $4^{\circ} \mathrm{C}$ resulted in only $1.4 \%$ of the tryptophol being recovered in the unbound fraction, and a similarly low dissociation constant $\left(K_{\mathrm{d}}=1.4 \mu \mathrm{M}\right)$ was calculated.

When BSA was replaced by normal rat serum in simi-

TABLE I

Brain Uptake of $\left[{ }^{3} \mathrm{H}\right]$ Tryptophol 5-240 s after Intracarotid Injection

\begin{tabular}{lcll}
\hline $\begin{array}{c}\text { Tryptophol } \\
\text { concentration }\end{array}$ & $\begin{array}{c}\text { Decapitation } \\
\text { time }\end{array}$ & BUI & \\
& $s$ & & $n$ \\
$10 \mathrm{mM}$ & 5 & $122 \pm 6$ & 3 \\
$1 \mathrm{mM}$ & 5 & $110 \pm 5$ & 3 \\
Trace $(+50 \%$ serum) & 5 & $104 \pm 3$ & 3 \\
Trace & 5 & $117 \pm 4$ & 6 \\
Trace & 15 & $124 \pm 2$ & 3 \\
Trace & 30 & $127 \pm 3$ & 3 \\
Trace & 60 & $127 \pm 24$ & 3 \\
Trace & 120 & $115 \pm 6$ & 3 \\
Trace & 240 & $116 \pm 12$ & 3 \\
\end{tabular}

Trace concentration of tryptophol injected was $<15 \mathrm{nM}$ in both these intracarotid studies, and in intravenous distributions (Table II). The high permeability of tryptophol (BUI $>100 \%$ ) in the $\mathrm{BBB}$ is demonstrated by comparison with nondiffusible and highly diffusible compounds. Butanol (the reference substance used in this study) is believed to be $100 \%$ cleared in a single capillary transit (50). Water has a BUI (relative to butanol) of $85 \%(50)$, whereas the BUIs of ethanol (about $88 \%$ ) and isopropanol (about 94\%) are higher (24). Nondiffusible substances have minimally low BUIs; e.g., tryptamine (about 9\%) (50), thiourea (about 4\%), and dextran (about 1\%) (51). 
lar studies, $6.14 \%$ of the tryptophol was recovered from the unbound fraction after $2 \mathrm{~h}$ at $37^{\circ} \mathrm{C}$, with $2.17 \%$ recovered unbound after $17 \mathrm{~h}$ at $4^{\circ} \mathrm{C}$.

Tissue distributions. As indicated in Table II, tissue distribution of tryptophol 2 min after intravenous injection seems to correlate with the relative blood flow to the tissues examined. For compounds which gain entry to tissues by virtue of their lipophilic properties, relative distribution would be expected to correlate with blood flow. This point is further emphasized in comparing distribution of a resting muscle
(Rectus femoris) with that seen in active muscles (e.g., diaphragm, ventricular myocardium). In addition, tryptophol distribution in the CNS was highest in the midbrain, presumably because relative blood flow to the corpora quadrigemina is markedly elevated (30). Lowest $\left({ }^{3} \mathrm{H}\right)$ uptakes were seen in low blood flow regions (fat, skin, testis, and resting skeletal muscle). The liver and renal cortex displayed highest relative concentrations of tritium, and these two organs receive almost one half of the total cardiac output under resting conditions (31). The Indium spaces (Table II) represent

TABLE II

Tissue Distribution of $\left[{ }^{3} \mathrm{H}\right] 2$ Min after Intravenous Injection of $\left[{ }^{3} \mathrm{H}\right]$ Tryptophol

\begin{tabular}{|c|c|c|c|c|}
\hline Tissue & $\begin{array}{l}\text { Indium } \\
\text { space }^{*}\end{array}$ & $\begin{array}{l}\text { Relative } \\
\text { blood flow }\end{array}$ & $\begin{array}{l}\text { Mean body } \\
\text { distribution } 1\end{array}$ & $\begin{array}{c}\text { Tissue:plasma } \\
\text { ratio }\end{array}$ \\
\hline & & $\%$ & $\%$ & \\
\hline Cortex & $0.030 \pm 0.001$ & 14 & $540 \pm 56$ & $0.428 \pm 0.07$ \\
\hline Thalamus & $0.010 \pm 0.004$ & 14 & $588 \pm 23$ & $0.863 \pm 0.17$ \\
\hline Midbrain & $0.014 \pm 0.004$ & 14 & $612 \pm 31$ & $0.895 \pm 0.14$ \\
\hline Cerebellum & $0.015 \pm 0.003$ & 14 & $544 \pm 22$ & $0.793 \pm 0.10$ \\
\hline Spinal cord $\S$ & $0.014 \pm 0.007$ & - & $461 \pm 19$ & $0.673 \pm 0.08$ \\
\hline Thyroid & $0.127 \pm 0.016$ & 1 & $640 \pm 92$ & $0.951 \pm 0.30$ \\
\hline Thymus & $0.022 \pm 0.005$ & - & $410 \pm 15$ & $0.602 \pm 0.12$ \\
\hline Lung & $0.267 \pm 0.115$ & 3 & $538 \pm 181$ & $0.818 \pm 0.39$ \\
\hline Muscle" & $0.011 \pm 0.005$ & - & $202 \pm 57$ & $0.292 \pm 0.07$ \\
\hline Heart & $0.097 \pm 0.008$ & 3 & $723 \pm 223$ & $1.054 \pm 0.32$ \\
\hline Diaphragm & $0.039 \pm 0.014$ & - & $568 \pm 210$ & $0.809 \pm 0.21$ \\
\hline Liver & $0.195 \pm 0.033$ & 27 & $1,437 \pm 68$ & $2.072 \pm 0.40$ \\
\hline Spleen & $0.117 \pm 0.020$ & $\sim 2 \ddagger$ & $510 \pm 81$ & $0.758 \pm 0.25$ \\
\hline Pancreas & $0.036 \pm 0.006$ & $\sim 2 \hbar \hbar$ & $847 \pm 201$ & $1.273 \pm 0.52$ \\
\hline Duodenum & $0.022 \pm 0.002$ & $\sim 5 \ddagger$ & $509 \pm 43$ & $0.752 \pm 0.19$ \\
\hline Large intestine & $0.020 \pm 0.003$ & $\sim 5 \ddagger \ddagger$ & $395 \pm 24$ & $0.575 \pm 0.06$ \\
\hline Kidney cortex & $0.144 \pm 0.014$ & 22 & $967 \pm 136$ & $1.434 \pm 0.44$ \\
\hline Adrenal & $0.125 \pm 0.015$ & 0.5 & $760 \pm 28$ & $1.113 \pm 0.20$ \\
\hline Perirenal fat & $0.009 \pm 0.003$ & - & $148 \pm 40$ & $0.220 \pm 0.08$ \\
\hline Skin & $0.026 \pm 0.001$ & - & $293 \pm 9$ & $0.430 \pm 0.07$ \\
\hline Lymph nodes** & $0.027 \pm 0.003$ & - & $349 \pm 67$ & $0.521 \pm 0.19$ \\
\hline Gonad (testis) & $0.007 \pm 0.001$ & - & $253 \pm 20$ & $0.374 \pm 0.09$ \\
\hline
\end{tabular}

As indicated in the text, little or no degradation of $\left[{ }^{3} \mathbf{H}\right]$ tryptophol occurs in this time period in the nervous system, and the BBB apparently excludes $\left[{ }^{3} \mathrm{H}\right]$ tryptophol metabolites formed peripherally. However, the non-CNS tissues may contain variable amounts of $\left[{ }^{3} \mathrm{H}\right]$ tryptophol and tryptophol metabolites. Urine samples (weighing 0.1-0.05 g) contained no significantly measurable quantities of tritium, suggesting that any tryptophol catabolites formed in this period had not yet been excreted by the kidneys.

* Because $113 \mathrm{~m}$-Indium-EDTA distributes after intravenous injection in a manner similar to extravascular space markers, the Indium space represents an estimate of the relative sizes of these compartments in the different tissues examined.

$\downarrow \%$ Mean body distribution $={ }^{3} \mathrm{H}$ disintegrations per minute per gram tissue/total ${ }^{3} \mathrm{H}$ disintegrations per minute injected per animal (total gram weight) $\times 100 \%$.

$\S$ Cervical spinal cord.

"Rectus femoris muscle.

"Ventricular myocardium.

** Mesenteric lymph nodes.

\# Estimates from Guyton (31, p. 377), other blood flow figures from Guyton (31, p. 251). 
a numerical quantification of the differing relative extracellular compartments in these tissues.

Extraction and TLC analysis of forebrains indicated that of the total tritium, $85 \pm 1 \%$ could be recovered as tryptophol 2 min after intravenous injection. No other discernable peaks were apparent in either the ether or aqueous phases, and the separatory procedure recovers only about $90 \%$ of the tryptophol. Therefore the $85 \%$ represents a conservative estimate, and there may be little, if any, catabolism of tryptophol by the brain in the 1st 2 min postinjection. Analysis of tissues sampled 5 min after intravenous injection of $\left[{ }^{3} \mathrm{H}\right]$ tryptophol further suggested that $88 \%$ (mean of duplicates) of the brain tritium co-migrated with tryptophol standards. In other tissues examined, lesser fractions of tryptophol were recovered: $24 \%$ from the liver, $44 \%$ from the lungs, $54 \%$ from the plasma, and $72 \%$ from the pancreas. (In these tissues, some degradation of the $\left[{ }^{3} \mathrm{H}\right]-$ tryptophol may have occurred between the time the rat was killed, and the weighed sample homogenized in Tris-azide.)

\section{DISCUSSION}

The complete clearance by the brain in one circulatory passage, the absence of saturable uptake, and the high partition coefficient (in octanol:water) observed in this study convincingly indicate that tryptophol freely penetrates the BBB by virtue of its lipid solubility. (Variation in the observed partition coefficient in this study and that of Seed et al. [16] [29.8 and 37.5, respectively] can be attributed to method differences.) This is consistent with the relationship described by Oldendorf (24) between partition coefficient and BBB penetration. Nicotine and imipramine, two highly lipophilic compounds, have brain uptake indices (determined relative to tritiated water, and without Indium correction) of $130 \%$. Their uptakes relative to butanol would be $110 \%$ (BUI water $\times 0.85=$ BUI butanol), quite comparable to the $117 \%$ value of tryptophol (see Table I) suggesting tryptophol is nearly $100 \%$ cleared in a single brain circulatory passage. These data are consistent with the rapid onset of CNS effects (sleep induction) seen with tryptophol administration.

A second point worthy of emphasis is that once tryptophol gains access to the brain, it apparently binds, or is altered so that it is not readily washed out of the CNS. The apparent increase in brain uptake seen at 5 , 15,30 , and $60 \mathrm{~s}$ after intracarotid injection of tryptophol (Table I) is presumably due to a slower washout of tryptophol from brain relative to the butanol reference.

The recovery of almost $90 \%$ of the brain radioactivity in the form of tryptophol at 2 and $5 \mathrm{~min}$ after intravenous injection further suggests that this compound is not rapidly metabolized by brain, and that the BBB may exclude peripherally formed tryptophol metabolites during this time period. Such a conclusion is apparently consistent with the recent study of Seed and Sechelski (32), who found highest levels of tryptophol in brains at $5 \mathrm{~min}$ postinjection, and coincidentally observed the absence of detectable levels of indole acetic acid (a tryptophol catabolite) in brain at this time. The apparently rapid alteration of $\left[{ }^{3} \mathrm{H}\right]$ tryptophol by the liver (only $24 \%$ of the radioactivity was recovered as tryptophol after $5 \mathrm{~min}$ ), seems consistent with previous suggestions that the liver is one of the principal sites for degradation of indole alcohols and indole acetaldehydes (13). In the recovery studies, a trace amount $(<125 \mathrm{nmol})$ of $\left[{ }^{3} \mathrm{H}\right]$ tryptophol was injected; it is therefore possible that at higher (pharmacological) concentrations, catabolism of tryptophol in vivo might not be as rapid as suggested by our isotopic studies.

The reduction in brain uptake of tryptophol seen in the presence of $50 \%$ normal rat serum suggested that this indole compound binds to the serum, and this was confirmed in subsequent in vitro dialysis studies. It is of considerable interest to note that at $37^{\circ} \mathrm{C}, 93 \%$ of the tryptophol remains bound to BSA, or with normal serum $94 \%$ of the tryptophol remains bound. On this basis, one would predict that the inclusion of $50 \%$ serum in the injectate should result in a significant reduction in brain uptake. ([\% bound $] /[\%$ free $]=[$ albumin concn $/ K_{\mathrm{d}}$; ; because $50 \%$ serum contains about $220 \mu \mathrm{M}$ albumin, and the $K_{\mathrm{d}}=3 \mu \mathrm{M}, 220 / 3=[\%$ bound] $/[\%$ free]. Thus about $98 \%$ of the tryptophol is albumin bound.) The observed reduction in BUI (Table I) was $<10 \%$. These data seem to be best explained by the previous report (33) indicating that albumin-bound indole compounds may be stripped away from the albumin and penetrate the BBB in a single transcapillary passage. The role of albumin binding in relation to brain tryptophan (and other indole amine) levels is a controversial subject. European investigators suggest that brain tryptophan concentration is a function of free tryptophan levels in the plasma (34-36). In contrast, American workers indicate that brain tryptophan concentrations correlate with total (free plus bound) plasma tryptophan levels $(37,38)$. This study demonstrates that in the case of this indole alcohol (which does not gain access to brain via a carrier mediated transport system), brain uptake is minimally affected by serum binding phenomena and thus is a function of total plasma tryptophol levels.

The penetration of tryptophan, an essential amino acid and source of the indole nucleus, into most tissues is carefully regulated by transport mechanisms in the cell membrane. In the $\mathrm{BBB}$, for example, tryptophan entry from both free and albumin bound sources is carefully regulated by these carrier systems $(33,39)$. The biological effect of indole alcohols such as trypto- 
phol and 5-hydroxytryptophol may well be due to their failure to be excluded by living membranes (a function of lipid solubility). These indoles consequently escape regulation by carrier systems and this presumably produces an imbalance of biochemical events surrounding indole metabolism.

This study demonstrates that the tryptophol is $100 \%$ cleared by the CNS in a single capillary transit. Thus, any tryptophol that reaches the circulatory system will gain access to this site. With relationship to pathological conditions such as alcoholism (tryptophol has been identified as a component of wine and beer [40]) and trypanosomal sleeping sickness, brain uptake of tryptophol will be directly proportional to the arterial concentration of this compound and blood flow to the brain. When tryptophol is formed in the liver, as in the Antabuse-treated rat (14), at least $14 \%$ (the fraction of cardiac output distributing to brain) of the amount released into the circulatory system will gain access to the brain (Table II).

In Antabuse-treated humans who take alcohol, there is an initial acutely unpleasant reaction lasting from 30 min to several hours, followed by a period of sleep lasting for several hours (41). Antabuse alone often induces sedation, and administration upon retiring is suggested for these patients (42). Recent animal studies also indicate that barbiturate-induced sleeping time is increased by concomitant administration of disulfiram $(43,44)$. Our studies and those of Smith and Wortis (14) collectively suggest the possibility that tryptophol formed in the liver and circulating to the brain might induce this period of sleep.

Furthermore, in trypanosomal sleeping sickness, tryptophol formed by circulating trypanosomes (as well as organisms in the CNS) could well be responsible for the tryptophol-induced soporific effects. Because indole ethanol and indole acetaldehyde compounds may be readily interconverted, the possibility that either of these two forms may be the biochemical moiety responsible for sleep induction is discussed by Feldstein (45). The penetration of tryptophol in lymphoid tissues such as the thymus, spleen, and mesenteric lymph nodes is of interest with respect to the recent observations of tryptophol-induced immunosuppression (20).

Tissue distributions of radioactive $\left[{ }^{14} \mathrm{C}\right] 5$-methoxytryptophol have been studied (46) 1,2 , and $6 \mathrm{~h}$ after intraperitoneal administration. This compound is formed in the pineal gland from 5-hydroxytryptophol and reduces ovarian weight as well as decreasing estrus in maturing rats (47). Delvigs et al. (46) suggest it is rapidly metabolized (as indicated by radioactivity in the urine), and additionally showed high levels in thyroid, adrenals, ovaries, and uterus. The possibility of systemic biotransformation in their studies cannot be overlooked. For this reason, and for other technical differences, further comparison between this study and that of Delvigs et al. (46) seemed unwarranted. In addition, one would predict that 5-methoxytryptophol would have a slightly lower partition coefficient in octanol:water and its brain uptake might consequently be reduced in comparison to tryptophol (48). A discussion of effects of hydroxylation and methoxylation in reducing brain uptake of compounds with structural similarities to biogenic amines appears elsewhere (48). Recent work indicates that serum concentrations of 5-methoxytryptophol correlate with levels measured in the pineal gland (49), and thus 5-methoxytryptophol might be expected to gain ready access to brain $(15,49)$.

This study raises the question as to whether the apparent effects of tryptophol seen in trypanosomal sleeping sickness, and in disulfiram-treated states result in identical or merely similar biochemical events. Because appropriate animal model systems are available for laboratory studies, the combined study of these two conditions could conceivably result in both an increased understanding of biochemical events attributable to tryptophol as well as employing comparative biochemistry to gain further insight into trypanosomiasis and alcoholism.

\section{ACKNOWLEDGMENTS}

We thank Dr. W. M. Pardridge, Stella Z. Oldendorf, Mr. Anthony M. Nyerges, and Mr. Richard Tanaka for their assistance.

This study was supported by National Institutes of Health grant AI 13228 (Dr. A. J. MacInnis), the National Institute of Alcohol Abuse and Alcoholism (AA03513), and the Veterans Administration.

\section{REFERENCES}

1. Guggenheim, M., and W. Loffler. 1916. Biologischer Nachweis proteinogener Amine in Organextraken und Korperflussigkeiten. Biochem. Z. 72: 303-324.

2. Ehrlich, F. 1912. Uber Tryptophol (B-Indolyl-athylalkohol), ein neues Garprodukt der Hefe aus Aminosauren. Ber. Deut. Chem. Ges. 45: 883-889.

3. Kveder, S., S. Iskric, and D. Keglevic. 1962. 5-hydroxytryptophol: a metabolite of 5-hydroxytryptamine in rats. Biochem. J. 85: 447-449.

4. Feldstein, A., and K. K. Wong. 1965. Enzymatic conversion of serotonin to 5-hydroxytryptophol. Life Sci. 4: 183-191.

5. McIssac, W. M., G. Farrell, R. G. Taborsky, and A. N. Taylor. 1965. Indole compounds: isolation from pineal tissue. Science (Wash. D. C.). 148: 102-103.

6. Davis, V. E., J. L. Cashaw, J. A. Huff, and H. Brown. 1966. Identification of 5-hydroxytryptophol as a serotonin metabolite in man. Proc. Soc. Exp. Biol. Med. 122: 890-893.

7. Eccleston, D., A. T. B. Moir, H. W. Reading, and I. M. 
Ritchie. 1966. The formation of 5-hydroxytryptophol in brain in vitro. Br. J. Pharmacol. Chemother. 28: 367-377.

8. Davis, V. E., H. Brown, J. A. Huff, and J. L. Cashaw. 1967. The alteration of serotonin metabolism to 5-hydroxytryptophol by ethanol ingestion in man. J. Lab. Clin. Med. 69: 132-140.

9. Tyce, G. M., E. V. Flock, and C. A. Owen. 1968. 5-hydroxytryptamine metabolism in brains of ethanol-intoxicated rats. Mayo Clin. Proc. 43: 668-673.

10. Feldstein, A., and O. Williamson. 1968. The effect of ethanol and disulfiram on serotonin-14-C metabolism in rat liver homogenates. Life Sci. 7: 777-783.

11. Feldstein, A., H. Hoagland, H. Freeman, and O. Williamson. 1967. The effect of ethanol ingestion on serotonin-C-14 metabolism in man. Life Sci. 6: 53-61.

12. Feldstein, A., and C. M. Sidel. 1969. The effect of ethanol on the in vivo conversion of 5-HTP 14-C to serotonin14-C, 5-hydroxyindole acetaldehyde 14-C and its metabolites in rat brain. Int. J. Neuropharmacol. 8: 347-351.

13. Keglevic, D., S. Kveder, and S. Iskric. 1968. Indoleacetaldehydes-intermediates in indolealkylamine metabolism. Adv. Pharmacol. 6 (Part A): 79-89.

14. Smith, A. A., and S. B. Wortis. 1960. Formation of tryptophol in the disulfiram-treated rat. Biochim. Biophys. Acta. 40: $569-570$.

15. Feldstein, A., F. H. Chang, and J. M. Kucharski. 1970. Tryptophol, 5-hydroxytryptophol and 5-methoxytryptophol induced sleep in mice. Life Sci. 9: 323-329.

16. Seed, J. R., T. M. Seed, and J. Sechelski. 1978. The biological effects of tryptophol (indole-3-ethanol): Hemolytic, biochemical and behavior modifying activity. Comp. Biochem. Physiol. 60C: 175-185.

17. Taborsky, R. G. 1971. 5-hydroxytryptophol: Evidence for its having physiological properties. Experientia (Basel). 15: 929-930.

18. Stibbs, H. H., and J. R. Seed. 1973. Chromatographic evidence for the synthesis of possible sleep-mediators in Trypanosoma brucei gambiense. Experientia. (Basel). 29: 1563-1565.

19. Stibbs, H. H., and J. R. Seed. 1973. Further studies on the metabolism of tryptophan in Trypanosoma brucei gambiense: cofactors, inhibitors, and end-products. Experientia (Basel). 31: 275-277.

20. Ackerman, S. B., and J. R. Seed. 1976. The effects of tryptophol on immune responses and its implications towards trypanosome-induced immunosuppression. Experientia (Basel). 15: 645-647.

21. Vogel, W. H. 1969. Physiological disposition of 5-methoxytryptamine and the rope climbing performance of rats. Psychopharmacologia. 15: 88-95.

22. Barofsky, I., and A. Feldstein. 1970. Serotonin and its metabolites; their respective roles in the production of hypothermia in the mouse. Experientia (Basel). 15: 990-991.

23. Cornford, E. M., L. D. Braun, and W. H. Oldendorf. 1978. Carrier mediated blood-brain barrier transport of choline and certain choline analogs. J. Neurochem. 30: 299-308.

24. Oldendorf, W. H. 1974. Lipid solubility and drug penetration of the blood barrier. Proc. Soc. Exp. Biol. Med. 147: 813-816.

25. Oldendorf, W. H., and J. Szabo. 1976. Amino acid assignment to one of three blood brain barrier amino acid carriers. Am. J. Physiol. 230: 94-98.

26. Oldendorf, W. H., and E. M. Cornford. 1977. A comparison of total body and local spinal cord irradiation in ex- perimental allergic encephalomyelitis. J. Neuropathol. Exp. Neurol. 36: 50-61.

27. Raj, R. K., and O. Hutzinger. 1969. Indoles and auxins. V. Separation of 2,4-dinitrophenylthio-derivatives of naturally occurring indoles by thin layer chromatography. J. Chromatogr. 44: 199-201.

28. Crane, P. D., L. D. Braun, E. M. Cornford, J. E. Cremer, J. M. Glass, and W. H. Oldendorf. 1978. Dose dependent reduction of glucose utilization by pentobarbital in the rat brain. Stroke. 9: 12-18.

29. Dunnett, C. W. 1964. New tables for multiple comparisons with a control. Biometrics. 20: 482-491.

30. Reivich, M. 1974. Blood flow metabolism couple in the brain. Res. Publ. Assoc. Res. Nerv. Ment.Dis. 53: 125- 140.

31. Guyton, A. C. 1976. Textbook of Medical Physiology. W. B. Saunders Co., Philadelphia, Pa. 5th edition. 281.

32. Seed, J. R., and J. Sechelski. 1977. Tryptophol levels in mice injected with pharmacological doses of tryptophol, and the effect of pyrazole and ethanol on these levels. Life Sci. 21: 1603-1610.

33. Yuwiler, A., W. H. Oldendorf, E. Geller, and L. D. Braun. 1977. Effect of albumin binding and amino acid competition on tryptophan uptake into brain. J. Neurochem. 28: 1015-1023.

34. Biggio, G., F. Fadda, P. Fanni, A. Tagliomonte, and G. L. Gessa. 1974. Rapid depletion of serum tryptophan, brain tryptophan, serotonin and 5-hydroxyindole acetic acid by a tryptophan-free diet. Life Sci. 14: 1321-1329.

35. Curzon, G., and P. J. Knott. 1974. Effects on plasma and brain tryptophan in the rat of drugs and hormones that influence the concentration of unesterified fatty acids in the plasma. Br. J. Pharmacol. 50: 197-204.

36. Fernando, J. C. R., P. J. Knott, and G. Curzon. 1976. The relevance of both plasma free tryptophan and insulin to rat brain tryptophan concentration. J. Neurochem. 27: 343-345.

37. Madras, B. K., E. L. Cohen, R. Messing, H. N. Munro, and R. J. Wurtman. 1974. Relevance of free tryptophan in serum to tissue tryptophan concentrations. Metab. Clin. Exp. 23: 1107-1116.

38. Fernstrom, J. D., M. J. Hirsch, and D. V. Faller. 1976. Tryptophan concentrations in the rat brain. Biochem. J. 160: 589-595.

39. Pardridge, IV. M. 1977. Kinetics of competitive inhibition of neutral amino acid transport across the blood brain barrier. J. Neurochem. 28: 103-108.

40. Nykanen, L., E. Puputti, and H. Suomalainen. 1966. Gas chromatographic determination of tyrosol and tryptophol in wines and beers. J. Inst. Brew. 72: 24-28.

41. Goodman, L. S., and A. Gilman. 1975. The Pharmacological Basis of Therapeutics. Mac.Millan Inc., New York. 5th edition. 148.

42. Physicians Desk Reference. 1978. Medical Economics Co., Oradell, N. J. 32nd edition. 592.

43. Stripp, B., F. E. Green, and J. R. Gillette. 1969. Disulfiram impairment of drug metabolism by rat liver microsomes. J. Pharmacol. Exp. Ther. 170: 347-354.

44. Sharkawi, M., and D. Cianflone. 1978. Disulfiram enhances pharmacological activity of barbital and impairs its urinary elimination. Science (Wash. D. C.). 210: 543544.

45. Feldstein, A. 1973. Ethanol-induced sleep in relation to serotonin turnover and conversion to 5-hydroxyindoleacetaldehyde, 5-hydroxytryptophol and 5-hydroxyindole acetic acid. Ann. N?. Y. Acad. Sci. 215: 71-76. 
46. Delvigs, P., W. M. McIsaac, and R. G. Taborsky. 1965. The metabolism of 5-methoxytryptophol. J. Biol. Chem. 240: 348-350.

47. McIsaac, W. M., R. G. Taborsky, and G. Farrell. 1964. 5-methoxytryptophol: effect on estrus and ovarian weight. Science (Wash. D. C.). 145: 63-64.

48. Oldendorf, W. H. 1971. Brain uptake of radiolabeled amino acids, amines, and hexoses after arterial injection. Am. J. Physiol. 221: 1629-1639.

49. Wilson, B. W., H. J. Lynch, and Y. Ozaki. 1978. 5-methoxytryptophol in rat serum and pineal: Determination, quantitation and evidence for daily rhythmicity. Life Sci. 23: 1019-1024.

50. Oldendorf, W. H., and L. D. Braun. 1976. 3-H Tryptamine and 3-H water as diffusible internal standards for measuring brain extraction of radiolabeled substances following intracarotid injection. Brain Res. 113: 219-224.

51. Cornford, E. M., L. D. Braun, P. D. Crane, and W. H. Oldendorf. 1978. Blood-brain barrier restriction of peptides and the low uptake of enkephalins. Endocrinology. 103: $1297-1303$. 